\title{
Impact of novel coronavirus Disease-19 (COVID-19) pandemic in Italian pediatric emergency departments: a national survey
}

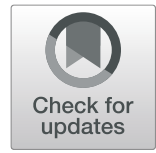

\author{
Valentina Talarico ${ }^{1 *}$ (D), Luciano Pinto ${ }^{2}$, Gian Luigi Marseglia ${ }^{3}$, Antonella Centonze ${ }^{4}$, Concetta Cristofaro ${ }^{5}$, \\ Rocco Reina ${ }^{5}$, Agostino Nocerino ${ }^{6}$, Riccardo Lubrano ${ }^{7}$, Stefania Zampogna ${ }^{1}$ and SIMEUP research group
}

\begin{abstract}
Background: Coronavirus Disease-19 (COVID-19) has rapidly become a pandemic emergency, distressing health systems in each affected country. Preparation strategies for managing this pandemic have been keys to face the COVID-19 surge all over the world and all levels of care.

Materials and Methods: During the epidemic, the Italian society of pediatric emergency-urgency (SIMEUP) promoted a national survey aiming to evaluate preparedness and response of pediatric emergency departments (PED) critical in ensuring optimal management of COVID-19 cases.

Results: Our results suggest that Italian PED have promptly set a proactive approach to the present emergency. 98.9\% of the hospitals have defined special pathways and assistive protocols concerning the management of pediatric COVID-19 cases. The highest percentage of application of the measures for preventive and protective for COVID-19 concerned the use of personal protective equipments.

Conclusions: Results show that the following measures for pediatric patients, admitted in PED, have been promptly implemented throughout the whole country: eg. use of protective devices, pre-triage of patients accessing the hospital. Despite COVID-19 being a new threat, we have shown that by developing an easy-to-follow decision algorithm and clear plans for the interventional platform teams, we can ensure optimal health care workers and patients' safety.
\end{abstract}

Keywords: Pediatric emergency, COVID-19, Personal protective equipment, Healthcare workers

\section{Background}

A novel coronavirus belonging to beta-coronavirus genera (named as 2019-nCoV by World Health Organization [WHO]) was identified as the causative agent associated with a cluster of cases of pneumonia detected in Wuhan City by Chinese authorities on 7 January [1, 2]. On January 2, 2020, the first 2 cases, two Chinese tourists, were identified in Italy; on January 30 ,

\footnotetext{
* Correspondence: talaricovalentina@gmail.com

'Department of Pediatric, "Pugliese-Ciaccio" Hospital, Viale Pio X, 88100 Catanzaro, Italy

Full list of author information is available at the end of the article
}

2020, WHO re-evaluated the potential effects of 2019$\mathrm{nCoV}$ infection in global public health, and declared this epidemic as a "Public Health Emergency of International Concern (PHEIC)". Since the discovery of 2019-nCoV, the virus has been rapidly spreading all over the word [3, 4]. Infected children might appear asymptomatic or have mild clinical manifestations: fever, dry cough, and fatigue, and few have upper respiratory symptoms including nasal congestion and running nose; some patients presented with gastrointestinal symptoms including abdominal discomfort, nausea, vomiting, abdominal pain, and diarrhea [5-8]. However, cases of major systemic

\section{$\triangle B M C$}

(c) The Author(s). 2021 Open Access This article is licensed under a Creative Commons Attribution 4.0 International License, which permits use, sharing, adaptation, distribution and reproduction in any medium or format, as long as you give appropriate credit to the original author(s) and the source, provide a link to the Creative Commons licence, and indicate if changes were made. The images or other third party material in this article are included in the article's Creative Commons licence, unless indicated otherwise in a credit line to the material. If material is not included in the article's Creative Commons licence and your intended use is not permitted by statutory regulation or exceeds the permitted use, you will need to obtain permission directly from the copyright holder. To view a copy of this licence, visit http://creativecommons.org/licenses/by/4.0/ The Creative Commons Public Domain Dedication waiver (http://creativecommons.org/publicdomain/zero/1.0/) applies to the data made available in this article, unless otherwise stated in a credit line to the data. 
inflammation (Kawasaki-Like Hyperinflammatory Syndrome) have been reported in children infected with coronavirus [9]. A study that involved a cohort of 100 Italian children younger than 18 years of age (The Coronavirus Infection in Pediatric Emergency Departments, CONFIDENCE) who were assessed between March 3 and March 27 in 17 Pediatric Emergency Departments (PED) (median age 3,3 years) observed that common symptoms were cough (in $44 \%$ of the patients) and no feeding or difficulty feeding (in 23\%). A total of 54 children (54\%) had a temperature of at least $37.6{ }^{\circ} \mathrm{C}$ and 12 (12\%) appeared ill, and 38 children (38\%) were admitted to the hospital; 20 of them had moderate or severe disease (19 and 1 respectively) [10]. Another study that involved 102 centers from 18 countries found a wide variation on personal protective equipment (PPE) use at pre-triage and for patient assessment [11]. Preparation strategies for managing this pandemic have been needed all over the world and in all the hospitals. Reallocation of resources in the management of this crisis implied careful planning, the interruption of scheduled hospitalizations, and the training of health workers. Strict adherence to infection control such as PEE and disinfection are the keys to contain the transmission of the disease. In particular, the key interventions of the PED for the management of this pandemic have been different. Mandatory hospitalization in isolation wards for all suspected cases presenting to the PED and the segregation of PED into high-risk, intermediate-risk, and low-risk areas are crucial elements for reduction the possible rate of infection [12].

The provision of qualified PPE to health care workers plays an essential role in preventing occupational exposure and infection. US Centers for Disease Control and Prevention for COVID-19 infection control of healthcare personnel recommended gloves, gowns, respiratory protection, and eye protection as standardized PPE [13].

The Italian society of pediatric emergency-urgency (SIMEUP) brings together various professional figures who manage children in the acute care setting, belonging to both general and pediatric hospitals. During the COVID-19 epidemic in Italy, the SIMEUP promoted a national survey aiming to evaluate the impact of COVID-19 on the clinical acute pediatric practice and the strategies activated at the hospital level for the management, infectious containment and reorganization of the work in the acute care pediatric setting during this pandemic.

\section{Material and methods}

We carried out an observational study on organizational changes that took place in Italy pediatric departments following the COVID-19 pandemic. The survey was launched online on 1st April 2020 and closed on 30th
April 2020. It included a total of 15 questions, divided into some large groups. The key points of the survey were:

- implementation of organizational protocol for the management of "suspected" or "confirmed" cases of pediatric COVID-19. In particular was asked whether there were specific regional, or local protocols for the management of pediatric COVID cases. A particular question was about there were hospital care pathways on specific aspects of the management of a COVID case (e.g. swab execution modality, bronchial or aspirate washing, hospitalization or transfer modalities, specific paths for newborns and/ or pregnant women)

- re-organization of spaces: we asked about the creation of dedicated pre-triage, with trained and qualified personnel, in particular if there were pediatric triages; the creation of waiting zones dedicated to children.

- use of PPE, before and after the pandemic, and ease of their procurement; we used a 5-point Linkert scale (1: never to 5: always) about the use of different PPE (in particular gloves, gowns, glasses, various type of facial masks, head cap, protective visor and shoe covers) and about the capacity of procurement PPE before and during the pandemic.

- modification of the emergency and planned work activities. The survey asked the number of visits to $\mathrm{PE}$ and the number of hospitalized children, during the month of March 2020 compared to the same period in the past year.

The questionnaire was sent to all SIMEUP members, made up of medical and nursing staff, coordinated by the SIMEUP regional presidents.

Descriptive statistics were used to analyze the data through the MedCalc Software (Ltd di Ostenda, Belgio).

\section{Results}

During the study period, we received the questionnaire replies from about 94 hospitals, of 20 Italian Region. The answers came from different health professionals (110 doctors, 30 nurses). The creation of specific organizational plans defined at a regional level, for the management of pediatric COVID-19 cases, occurred in about $63.8 \%$ Italian regions. However, almost $96.6 \%$ of the individual hospitals contributed to the creation of special pathways and assistive protocols concerning the management of COVID-19 cases for both adult and pediatric age. The most important structural modification consisted in the creation of pre-triage areas, as described in Fig. 1. About 98\% of the hospitals has created 


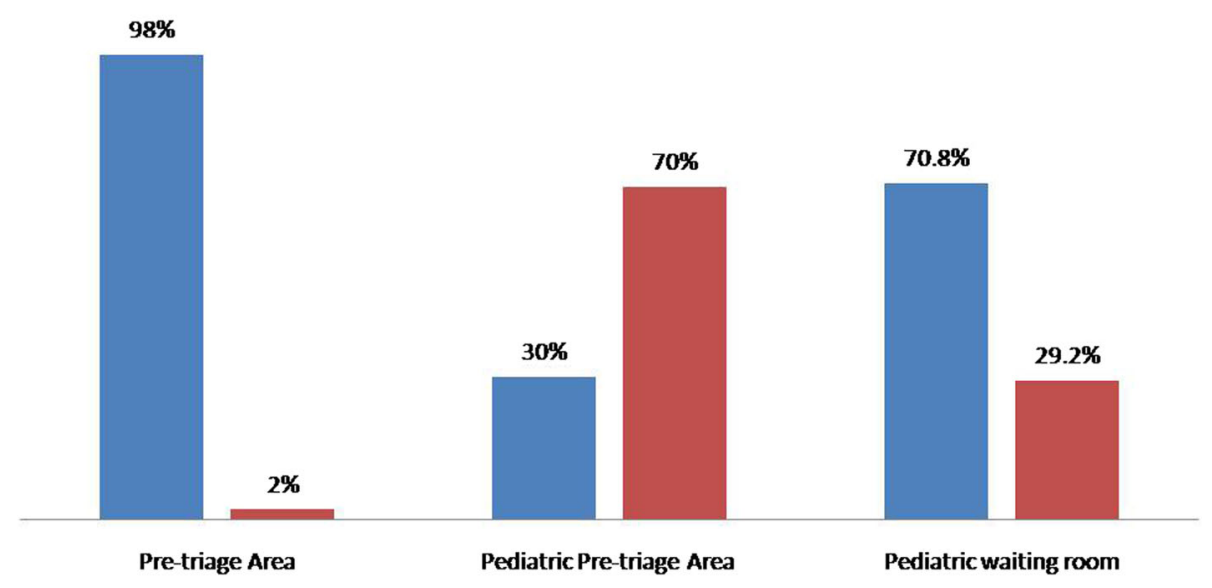

Fig. 1 Creation of specific areas in PED

a special pre-triage, but only in $30 \%$ of cases, it was dedicated to the pediatric age.

The hospital directives mainly concerned the use of PPE (95\%), the methods of performing the nasopharyngeal swab (85.71\%), the hospitalization of infectious subjects (84.29) and their transfer to other hospitals (Fig. 2). Interestingly, over $75 \%$ of hospitals have defined their own care pathway for the management of a mother or newborn infected with COVID 19.

About PPE, Table 1 shows the changes in the usual use of PPE before and after the pandemic. A positive trend is evident in the use of all devices, in particular the surgical mask (222.54\%). This trend of greatest use is uniform for both medical and nursing figures (Table 2). The percentage of use of PPE in the "Suspected" and "Confirmed" cases of COVID-19 was correctly distributed throughout the national territory (Table 3 ).
The ability to find PPE in the daily work of health professionals before and after the pandemic is represented in Table 4.

The comparison of PED visits and the number of admissions between March 2019 and 2020, showed that there was an overall reduction of $75.58 \%$ for emergency visits $(-72.566)$ and $68.42 \%$ for admissions $(-8.188)$. In 15 out of 94 hospitals, pediatric beds were used to care for adult infected by Covid-19 patients during that time.

\section{Discussion}

According to the Statistical Yearbook of the National Health System (published in 2019), in Italy there were 518 public hospital structures, 414 with a General Emergency Room (79.9\%) and 90 with a Pediatric Emergency Room (17.5\%) The survey was attended by 94 hospitals representing all the Italian regions (with the exception of

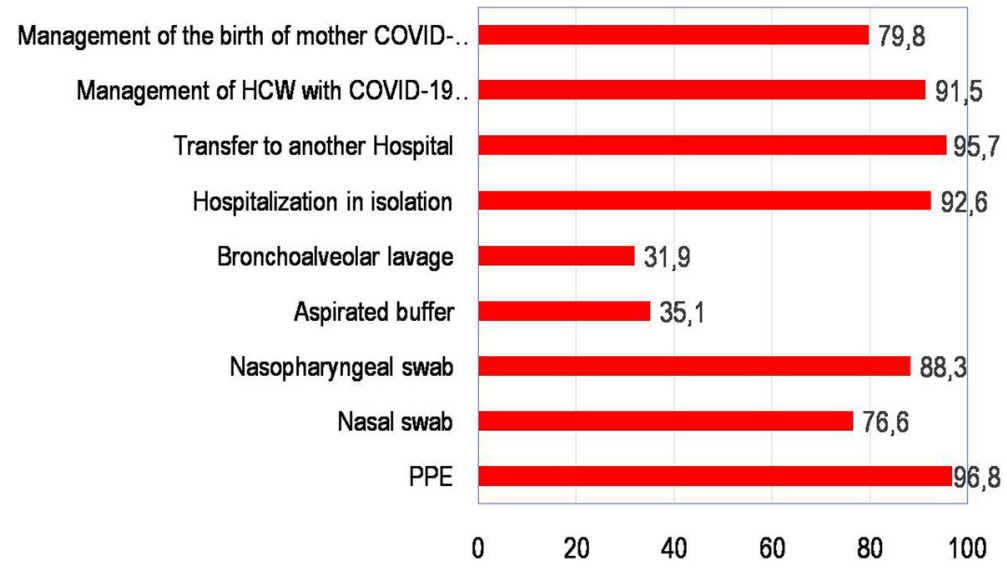

Fig. 2 Application of protective and preventive measures for COVID-19 
Table 1 Usual use of PPE before and after the onset of COVID-19 min 1(never)- max 5 (always)

\begin{tabular}{lllllllllll}
\hline & $\begin{array}{l}\text { Double } \\
\text { gloves }\end{array}$ & $\begin{array}{l}\text { Disposable } \\
\text { gown }\end{array}$ & $\begin{array}{l}\text { Waterproof } \\
\text { gown }\end{array}$ & $\begin{array}{l}\text { Surgical } \\
\text { face mask }\end{array}$ & $\begin{array}{l}\text { FFP2 } \\
\text { without } \\
\text { valve }\end{array}$ & $\begin{array}{l}\text { FFP2 with } \\
\text { valve }\end{array}$ & FFP3 Goggles & $\begin{array}{l}\text { Surgical } \\
\text { head cap }\end{array}$ & $\begin{array}{l}\text { Protective } \\
\text { Visor }\end{array}$ & $\begin{array}{l}\text { Shoe } \\
\text { covers }\end{array}$ \\
\hline $\begin{array}{l}\text { Before } \\
\text { COVID-19 }\end{array}$ & 2,78 & 1,93 & 1,19 & 1,42 & 2,26 & 1,27 & 1,31 & 1,74 & 1,58 & 1,72 \\
$\begin{array}{l}\text { After } \\
\text { COVID-19 }\end{array}$ & 4,37 & 3,83 & 2,84 & 4,58 & 2,31 & 2,71 & 2,13 & 3,40 & 3,54 & 3,13 \\
$\begin{array}{l}\text { Variation } \\
(\%)\end{array}$ & 1,59 & 1,91 & 1,65 & 3,16 & 0,05 & 1,44 & 0,81 & 1,66 & 1,96 & 1,41 \\
\hline
\end{tabular}

PPE personal protective equipment

the autonomous province of Trento) [14]. The results of the study suggest how the Italian PEDs have promptly taken action to manage the pandemic with standardized pathways and protocols.

World literature data shows that one of the most important actions that have been activated to manage the emergency from coronavirus has been to take urgent actions to reorganize health services and protect health workers to take care of patients with COVID-19 in safety and save lives. The COVID-19 outbreak has highlighted a gap between infectious disease healthcare and epidemiologist advice for preventing the spread of the disease versus the actions taken by the state authorities that in many cases have been too late and inadequate [15].

The hospital preparedness for epidemics and pandemics of COVID-19 has taught us several lessons, which deviate from the classical safety and protection protocols for healthcare personnel those who remain on the frontline, fighting against the further spread and tirelessly treating those who are diseased [15]. Due to a lack of sufficient awareness of the COVID-19 in the early stages of the epidemic, some healthcare workers (HCWs) have been infected [16].

Following the Chinese model, containment measures to reduce the risk of COVID-19 in Italy have been promptly activated and implemented [17]. Due to the necessity to set up emergency management protocols for the prevention and control novel coronavirus (2019$\mathrm{nCoV}$ ) infection spread, various hospitals have completely reorganized their work and space. As highlighted in our work, almost all Italian hospitals have defined specific pathways for pediatric cases of COVID-19, with the creation of dedicated pre-triage structures, sometimes only for children (30\%).

Numerous pediatric departments, both in Italy and in the rest of the world, had to initiate a series of structural and organizational changes to manage this pandemic. For example, the American pediatric response to the COVID-19 pandemic implemented change in 4 domains: physical space, clinical services, staffing models, and leadership. The goal was to continue to provide outstanding and safe pediatric care while at the same time supporting the adult emergency COVID-19 crisis [18].

Table 2 Usual use of PPE before and after the onset of COVID-19 for different healthcare workers min 1 (never)- max 5 (always)

\begin{tabular}{|c|c|c|c|c|c|c|c|c|}
\hline \multirow[t]{3}{*}{ PPE } & \multicolumn{4}{|l|}{ Nurse } & \multicolumn{4}{|l|}{ Doctor } \\
\hline & \multicolumn{2}{|l|}{ Before } & \multicolumn{2}{|l|}{ After } & \multicolumn{2}{|l|}{ Before } & \multicolumn{2}{|l|}{ After } \\
\hline & Media & $\overline{S D}$ & Media & $\overline{S D}$ & Media & $\overline{S D}$ & Media & $\overline{S D}$ \\
\hline Double gloves & 3,88 & 1,09 & 4,40 & 1,15 & 2,50 & 1,07 & 4,39 & 0,96 \\
\hline Disposable gown & 2,16 & 1,03 & 3,80 & 1,32 & 1,87 & 1,04 & 3,86 & 1,20 \\
\hline Surgical mask & 1,68 & 1,04 & 4,28 & 1,40 & 1,34 & 0,74 & 4,72 & 0,83 \\
\hline Waterproof gown & 1,25 & 0,64 & 3,17 & 1,47 & 1,16 & 0,41 & 2,78 & 1,33 \\
\hline FFP2 without valve & 2,39 & 1,08 & 2,72 & 1,28 & 2,23 & 1,03 & 2,23 & 1,21 \\
\hline FFP2 with valve & 1,30 & 0,63 & 3,04 & 1,55 & 1,25 & 0,56 & 2,64 & 1,35 \\
\hline FFP3 & 1,52 & 0,85 & 2,64 & 1,41 & 1,23 & 0,55 & 2,02 & 1,26 \\
\hline Surgical head cap & 2,12 & 1,01 & 3,92 & 1,35 & 1,64 & 0,99 & 3,43 & 1,31 \\
\hline Glasses & 1,88 & 0,93 & 3,52 & 1,29 & 1,48 & 0,88 & 3,39 & 1,28 \\
\hline Protective visor & 1,59 & 0,85 & 3,23 & 1,38 & 1,74 & 1,10 & 3,10 & 1,43 \\
\hline Shoe covers & 1,41 & 0,85 & 3,27 & 1,42 & 1,34 & 0,80 & 2,73 & 1,40 \\
\hline
\end{tabular}

PPE personal protective equipment, $S D$ standard deviation 
Table 3 Use of PPE in "suspected" and confirmed" case of COVID-19

\begin{tabular}{|c|c|c|c|c|c|c|c|c|c|c|c|}
\hline CASE & $\begin{array}{l}\text { Double } \\
\text { gloves }\end{array}$ & $\begin{array}{l}\text { Disposable } \\
\text { gown }\end{array}$ & $\begin{array}{l}\text { Waterproof } \\
\text { gown }\end{array}$ & $\begin{array}{l}\text { Surgical } \\
\text { facial mask }\end{array}$ & $\begin{array}{l}\text { FFP2 } \\
\text { without } \\
\text { valve }\end{array}$ & $\begin{array}{l}\text { FFP2 with } \\
\text { valve }\end{array}$ & FFP3 & Glasses & $\begin{array}{l}\text { Surgical } \\
\text { head cap }\end{array}$ & $\begin{array}{l}\text { Protective } \\
\text { Visor }\end{array}$ & $\begin{array}{l}\text { Shoe } \\
\text { covers }\end{array}$ \\
\hline Suspected & 96,24 & 83,33 & 85,04 & 71,82 & 56,64 & 73,83 & 41,24 & 92,13 & 94,49 & 82,79 & 76,27 \\
\hline Confirmed & 99,20 & 67,96 & 96,72 & 51,52 & 58,76 & 62,22 & 58,42 & 89,74 & 98,33 & 90,08 & 89,26 \\
\hline $\begin{array}{l}\text { Variation } \\
\text { (\%) }\end{array}$ & 2,96 & $-15,37$ & 11,68 & $-20,30$ & 2,13 & $-11,61$ & 17,18 & $-2,38$ & 3,85 & 7,30 & 12,99 \\
\hline
\end{tabular}

PPE personal protective equipment

To prevent the spread of COVID-19 to healthcare workers, additional infection control measures were implemented. Mask fitting exercises and PPE training was provided to all healthcare personnel. The most important PPE includes an N95 mask, eye protection with goggles or an eye shield, gown, and gloves [19].

The type and amount of PPE that should be used when treating a patient with COVID19 varies based on clinical job and setting [20]. For HCWs providing direct inpatient care for patients with COVID-19, a medical mask, gown, gloves, and eye protection in the form of goggles or a face shield should be used. If aerosolgenerating procedures are being performed, healthcare workers should also wear an apron and use an N95 respirator in the place of a surgical mask [21]. All these indications have been respected in all pediatric departments in our nation; as can be seen in Table 1, there has been an increase in the use of PPE after the pandemic in all HCWs.

This data, especially in the early stages of the pandemic, inevitably led, as emerged in our work, to a significant difficulty in the procurement of PPE.

All these structural changes in hospitals, and the increase in the use of PPE, inevitably had a major economic impact. Tassa Tan-Torres et al. have recently published a study on the expected economic needs for an adequate response to covid-19. They conclude that the costs of a response to COVID-19 in the healthcare sector will increase considerably, particularly if transmission increases, but putting in place early and comprehensive measures to limit the further spread of the virus will conserve resourced and support the response [22].

Finally, another important fact that emerges from our investigation was the reduction of pediatric emergency visits hospitalizations across the nation. Our results show a reduction of approximately $70 \%$ for both visits to pediatric emergency departments and in the number of hospitalizations. However, as highlighted in another study, given the reduction rate in the number of accesses, the children were referred to the ED more frequently by physicians or the out-of-hospital emergency system, and for reasons that were more frequently urgent [23]. The substantial decreases in pediatric care access in Italy might reflect the scarcity of available resources due to pandemic-related redistribution, or reticence on the part of parents and caregivers to risk exposure to severe acute respiratory syndrome coronavirus-2 (SARS-CoV-2) in a health-care setting, in addition to lower rates of acute infections and trauma [24]. There is a need to prevent delays in accessing hospital care and to increase the provision of high-quality coordinated care by health-care providers.

Both of these aspects should be considered as part of the overall public health impact of the COVID-19 pandemic, as evident in other epidemics [25] and must be adequately monitored. Both the general population and health-care workers need clear guidance and information. Specifically, parents should be made fully aware that the risks of delayed access to hospital care for emergency conditions can be much higher than those posed by COVID-19.

The authors acknowledge the non-uniformity and selection bias limitations associated with non-random convenience sampling in surveys, while recognizing the generalizability and internal and external validity of the survey approach.

The sample size is relatively low and there is likely to be variability in the practices observed between different health professionals, hospitals, and regions with varying prevalence. However, we believe that the results obtained may be explanatory of the real situation in which the PED lived during the first months of the COVID 19 pandemic wave.

Table 4 Difficulties in procuring protective equipment before and after the onset of COVID-19

\begin{tabular}{llllll}
\hline & Gloves & Facial mask & Disposable gown & Glasses & Disinfectants \\
\hline After COVID-19 & 3,98 & 3,22 & 3,44 & 3,53 & 3,75 \\
Before COVID-19 & 4,18 & 3,93 & 3,97 & 3,76 & 4,05 \\
Variation & $-0,21$ & $-0,71$ & $-0,53$ & $-0,23$ & $-0,30$ \\
Percentage of reduction (\%) & 4,96 & 18,06 & 13,38 & 6,18 & 7,36 \\
\hline
\end{tabular}




\section{Conclusions}

Although the pediatric age was not severely affected by SARS-CoV2, it was not completely spared. Initial data from the Chinese Center for Disease Control and Prevention which evaluated case series of 2143 pediatric patients with COVID-19 showed that although the majority of cases had mild or no symptoms, severe and critical cases were present in 10.6, and $7.3 \%$, for the age groups $<1$ and 1-4 years [26], and a large US study revealed that children may be a potential source of contagion in the SARS-CoV-2 pandemic even in the absence of symptoms [27]. Two Italian descriptive studies during the first months of the pandemic reported respectively that $8.5 \%$ had moderate disease, $8.5 \%$ had a severe disease and $6.9 \%$ had a critical presentation [28] and that $43 \%$ had been hospitalized, confirming that, although severe cases are rare, children may represent a source of viral transmission [29].

This new global challenge represented by COVID-19 has proven how fundamental it is to strengthen health systems, but also the ability to produce rapid reorganization of the provision of services to respond to COVID-19, while at the same time the basic essential services worked through the continuous care so that nobody was left behind. The prompt activation and implementation of containment measures to reduce the risk of COVID-19 in Italy, together with the attention and reorganization of Hospitals and Departments, further reduced the risk of transmission of the infection.

As we refined our understanding of COVID-19, a high degree of active surveillance in the community and dynamic reassessment of pediatric department workflow processes, in conjunction with the hospital and nationwide public health response, helped us better manage this ongoing pandemic and prepare for the next.

\section{Abbreviations}

COVID-19: Coronavirus Disease-19; HCWs: healthcare workers; PEE: personal protective equipment; PED: pediatric emergency departments; SARS-CoV2: severe acute respiratory syndrome coronavirus 2; SIMEUP: Italian society of pediatric emergency-urgency

\section{Acknowledgements}

\section{SIMEUP research group.}

Alberto Arrighini, $\mathrm{MD}^{8}$, Maria Antonietta Barbieri, $\mathrm{MD}^{9}$, Claudia Bondone ${ }^{10}$ MD, Silvia Bressan, MD ${ }^{11}$, Vincenza Corsi, $\mathrm{MD}^{12}$, Massimo Chiossi, MD ${ }^{13}$, Elisabetta Cortis, $\mathrm{MD}^{14}$, Laura Crespin, $\mathrm{MD}^{15}$, Antonio Cualbu, MD ${ }^{12}$, Liviana Da Dalt, Phd ${ }^{11}$, Valeria De Donno, MD ${ }^{16}$, Maria De Filippo, MD ${ }^{3}$, Antonella Di Stefano, $\mathrm{MD}^{17}$, Pasquale Ferrante, $\mathrm{MD}^{18}$, Battista Guidi, MD ${ }^{19}$, Adima Lamborghini, MD ${ }^{20}$, Marcello Lanari, PhD ${ }^{21}$, Cristina Malorgio, MD ${ }^{22}$, Sergio Manieri, MD ${ }^{23}$, Stefano Masi, MD²4, Susanna Masiero, MD ${ }^{11}$, Beatrice Messini, $\mathrm{MD}^{14}$, Maria Pia Mirauda, MD ${ }^{23}$, Anna Maria Musolino, MD' ${ }^{9}$, Rosaria Nigro, $\mathrm{MD}^{25}$, Giuseppe Parisi, MD ${ }^{26}$, Niccolò Parri, MD ${ }^{24}$, Massimo PettoelloMantovani, PhD ${ }^{27}$, Flavio Quarantiello, MD ${ }^{28}$, Eduardo Ponticiello, MD ${ }^{29}$, Stefano Romero, $M D^{30}$, Salvatore Savasta, $M D^{31}$, Eurilla Sequi, $M D^{31}$, Debora M.L. Simonetti, $\mathrm{MD}^{33}$, Eleonora Tappi, $\mathrm{MD}^{34}$, Antonio Francesco Urbino ${ }^{10}, \mathrm{MD}$, Patrizia Vianelli, $\mathrm{MD}^{35}$, Tiziana Zangardi, $\mathrm{MD}^{10}$.

Affiliations

${ }^{8}$ Pediatric Emergency Department, Presidio Ospedale dei Bambini, A.O. Spedali Civili, Brescia, Italy.
${ }^{9}$ Pediatric Emergency Department, Bambino Gesù Children's Hospital, Istituto di Ricovero e Cura a Carattere Scientifico, Rome, Italy.

${ }^{10}$ Department of Pediatric Emergency, Regina Margherita Children's Hospital - A.O.U. Città della Salute e della Scienza di Torino, Turin, Italy.

${ }^{11}$ Division of Pediatric Emergency Medicine, Department of Women's and

Children's Health, University of Padova, Italy.

12 Department of Pediatrics, San Francesco Hospital of Nuoro, Italy.

${ }^{13}$ Department of Pediatrics and Neonatology, Hospital of Lavagna, Italy.

14 Paediatric Unit, San Giovanni Battista Hospital of Foligno, Italy.

15 Department of Pediatrics, Valle del Serchio Hospital, Italy.

${ }^{16}$ Department of Pediatrics, S. Croce e Carle Hospital of Cuneo, Italy.

17 Department of Pediatrics, Cannizzaro Hospital of Catania, Italy.

${ }^{18}$ Department of Pediatrics and Neonatology, "L Bonomo" Hospital of

Andria, ASL BT, Italy.

${ }^{19}$ Paediatric Unit, AUSL of Modena, Pavullo nel Frignano, Italy.

20 Department of Pediatrics, Asl di Teramo, Italy.

${ }^{21}$ Pediatric Emergency Department, S. Orsola Hospital, Bologna, Italy.

22 Department of pediatrics and neonatology, Valduce Hospital, Como, Italy.

23 Department of Pediatrics, San Carlo Hospital, Potenza, Italy.

${ }^{24}$ Department of Pediatric Emergency Medicine and Trauma Center, Meyer

University Children's Hospital, Florence, Italy.

${ }^{25}$ Department of Pediatrics, lannelli Hospital of Cetraro, Italy.

${ }^{26}$ Department of Pediatrics, Anna Rizzoli Hospital, Ischia Island, ASL Naples 2 Nord, Italy.

27 Department of Pediatrics, Scientific Institute "Casa Sollievo della

Sofferenza", University of Foggia, Foggia, Italy.

${ }^{28}$ Department of Pediatric and Adolescent Medicine, A.O San Pio,

Benevento, Italy.

${ }^{29}$ Pediatric Emergency Department, Santobono-Pausilipon Hospital, Napoli, Italy.

${ }^{30}$ Department of pediatrics, San Pietro Fatebenefratelli Hospital, Roma, Italy.

31 Pediatric Unit, Senior Hospital of Crema, Italy.

32 Department of Neonatology, "Nostra Signora Bonaria" San Gavino

Monreale, Italy.

33 Pediatric Unit, "A. Cardarelli" Hospital. ASREM- Campobasso,ltaly.

34 Department of Pediatric, "S.Croce e Carle" Hospital of Cuneo, Italy.

${ }^{35}$ Department of Pediatric, Salesi Hospital of Ancona, Italy.

\section{Authors' contributions}

$V T, L P, A C, A N, R L, S Z$ contributed to the conception and writing of this manuscript; VT, GLM, CC, RR, and SZ critically reviewed the manuscript and supervised the whole study process. SIMEUP study group are the managers of centers that provided the data. Each author should have participated sufficiently in the work to take public responsibility for appropriate portions of the content. All authors read and approved the final manuscript.

\section{Funding}

Authors also declare any financial support.

Availability of data and materials

This manuscript has not been published and is not under consideration for publication elsewhere. The data presented are original.

Ethics approval and consent to participate

We obtain ethical approval and consent of all centers to participate to the study.

Consent for publication

All the information provided have been approved by all the authors.

\section{Competing interests}

The authors declared no potential conflicts of interests with respect to the authorship and/or publication of this article.

\section{Author details}

'Department of Pediatric, "Pugliese-Ciaccio" Hospital, Viale Pio X, 88100 Catanzaro, Italy. ${ }^{2}$ Italian Society of Pediatric Emergency Medicine, Naples, Italy. "Department of Pediatrics, Foundation IRCCS Policlinico "San Matteo" University of Pavia, Pavia, Italy. ${ }^{4}$ Department of Pediatric Surgery,

"Pugliese-Ciaccio" Hospital, Viale Pio X, Catanzaro, Italy. ${ }^{5}$ Department of Law, History Economics and Social Science, Magna Graecia University, Catanzaro, 
Italy. ${ }^{6}$ Department of Pediatrics, University Hospital of Udine, Udine, Italy. 7Department of Pediatrics, "La Sapienza" University of Roma -Hospital of Latina, Roma, Italy.

Received: 16 September 2020 Accepted: 16 February 2021

Published online: 03 March 2021

\section{References}

1. World Health Organization. WHO Statement Regarding Cluster of Pneumonia Cases in Wuhan, China. Available from URL: https://www.who. int/china/news/detail/09-01-2020-who-statement-regarding-cluster-ofpneumonia-cases-in-wuhan-china.

2. Li W, Zhou Q, Tang Y, et al. COVID-19 evidence and recommendations working group. Protocol for the Development of a Rapid Advice Guideline for Prevention, Management and Care of Children With 2019 Novel Coronavirus Infection. Ann Palliat Med. 2020;9(4):2251-5.

3. National Health Commission of The People's Republic of China. Interim protocol of diagnosis and treatment of 2019 Novel coronavirus-associated pneumonia (the second version). Available from URL: www.nhc.gov.cn/jkj/s3 577/202001/c67cfe29ecf1470e8c7fc47d3b751e88.shtml.

4. Zhu N, Zhang $D$, Wang $W$, et al. A novel coronavirus from patients with pneumonia in China, 2019. N Engl J Med. 2020;382:727-33. https://doi.org/1 0.1056/NEJMoa2001017.

5. Chan JF, Yuan S, Kok KH, et al. A familial cluster of pneumonia associated with the 2019 novel coronavirus indicating person-to-person transmission: a study of a family cluster. Lancet. 2020;395(10223):514-23. https://doi.org/1 0.1016/S0140-6736(20)30154-9.

6. Cai JH, Wang XS, Ge YL, et al. The first case report of 2019 novel coronavirus infection in children in Shanghai. Zhonghua Er Ke Za Zhi. 2020; 58(2):86-7. https://doi.org/10.3760/cma.jissn.0578-1310.2020.02.002.

7. Huang C, Wang Y, Li X, et al. Clinical features of patients infected with 2019 novel coronavirus in Wuhan, China. Lancet. 2020;395(10223):497-506. https://doi.org/10.1016/S0140-6736(20)30183-5.

8. Castagnoli R, Votto M, Licari A, et al. Severe Acute Respiratory Syndrome Coronavirus 2 (SARS-CoV-2) Infection in Children and Adolescents: A Systematic Review. JAMA Pediatr. 2020. https://doi.org/10.1001/jamapedia trics.2020.1467.

9. Verdoni L, Mazza A, Gervasoni A, et al. An outbreak of severe Kawasaki-like disease at the Italian epicentre of the SARS-CoV-2 epidemic: an observational cohort study. Lancet. 2020;395(10239):1771-8. https:/doi. org/10.1016/S0140-6736(20)31103-X.

10. Parri M, Lenge $M$, Buonsenso D. Coronavirus Infection in Pediatric Emergency Departments (CONFIDENCE) Research Group. Children With Covid-19 in Pediatric Emergency Departments in Italy. N Engl J Med. 2020: c2007617. https://doi.org/10.1056/NEJMc2007617.

11. Bressan S, Buonsenso D, Farrugia R, et al. Preparedness and response to Pediatric CoVID-19 in European Emergency Departments: a survey of the REPEM and PERUKI networks. Ann Emerg Med. 2020. https://doi.org/10.101 6/j.annemergmed.2020.05.018.

12. Ren Tan RM, Yong-Kwang Ong G, Chong SL, et al. Dynamic adaptation to COVID-19 in a Singapore Paediatric emergency department. Emerg Med J. 2020;37(5):252-4. https://doi.org/10.1136/emermed-2020-209634.

13. Cao Y, Li Q, Chen J, Guo X, Miao C, Yang H, Chen Z, Li C, Li L. Hospital emergency management plan during the COVID-19 epidemic. Acad Emerg Med. 2020;27(4):309-11. https://doi.org/10.1111/acem.13951.

14. Ministero della Salute _ Annuario Statistico del Servizio Sanitario Nazionale Assetto organizzativo, attività e fattori produttivi del SSN - Anno 2017. http://www.salute.gov.it/imgs/C_17_pubblicazioni_2879_allegato.pdf

15. Petrovski BE, LumiX ZL, Ivastinović D, Confalonieri F, Petrovič MG, Petrovski G. Reorganize and survive-a recommendation for healthcare services affected by COVID-19-the ophthalmology experience. Eye (Lond). 2020;34(7): 1177-9. https://doi.org/10.1038/s41433-020-0871-7.

16. data, G.F.b.o.l., Coronavirus: 2,629 infected docs, nurses. 2020. https://www.a nsa.it/english/news/general_news/2020/03/18/coronavirus-2629-infecteddocs-nurses_1bc5c6dc-baf0-467c-9ac8-e08bead819e0.html.

17. Indini A, Aschele C, Cavanna L, Clerico M, Daniele B, Fiorentini G, et al. Reorganization of medical oncology departments during the novel coronavirus disease-19 pandemic: a Nationwide Italian survey. Eur J Cancer. 2020;132:17-23. https://doi.org/10.1016/j.ejca.2020.03.024.

18. Fraymovich S, Levine DA, Platt SL. A blueprint for pediatric emergency resource reallocation during the COVID-19 pandemic: an NYC hospital experience. Pediatr Emerg Care. 2020 Sep;36(9):452-4. https://doi.org/10.1 097/PEC.0000000000002203.

19. World Health Organization. Infection prevention and control during health care when COVID-19 is suspected: interim guidance, 19 March 2020. Institutional Repos Inf Shar; 2020. p. 7.

20. Godoy LRA, Jones AE, Anderson TN, Fisher CL, Seeley KML, Beeson EA, et al. Facial protection for healthcare workers during pandemics: a scoping review. BMJ Glob Health. 2020;5(5):e002553. https://doi.org/10.1136/bmjgh-2 020-002553.

21. World Health Organization. Rational use of personal protective equipment (PPE) for coronavirus disease (COVID-19): interim guidance, 19 March 2020 Institutional Repos Inf Shar; 2020. p. 7.

22. Edejer TT, Hanssen O, Mirelman A, Verboom P, Lolong G, Watson OJ, Boulanger LL, Soucat A. Projected health-care resource needs for an effective response to COVID-19 in 73 low-income and middle-income countries: a modelling study. Lancet Glob Health. 2020 Nov;8(11):e1372-9. https://doi.org/10.1016/S2214-109X(20)30383-1.

23. Clavenna A, Nardelli S, Sala D, Fontana M, Biondi A, Bonati M. Impact of COVID-19 on the pattern of access to a pediatric emergency Department in the Lombardy Region. Italy Pediatr Emerg Care. 2020 Oct;36(10):e597-8. https://doi.org/10.1097/PEC.0000000000002232.

24. Lazzerini M, Barbi E, Apicella A, Marchetti F, Cardinale F, Trobia G. Delayed access or provision of Care in Italy Resulting from Fear of COVID-19. Lancet Child Adolesc Health. 2020;4(5):e10-1. https://doi.org/10.1016/S2352-4642 (20)30108-5.

25. Chang HJ, Huang N, Lee CH, Hsu YJ, Hsieh CJ, Chou YJ. The impact of the SARS epidemic on the utilization of medical services: SARS and the fear of SARS. Am J Public Health. 2004;94(4):562-4. https://doi.org/10.2105/ajph. 94.4.562.

26. Yuanyuan D, Xi MO, Yabin HU, Xin Ql, Fan J, Zhongyi J, Shilu T. Epidemiology of COVID-19 Among Children in China. Pediatrics. 2020;145(6): e20200702. https://doi.org/10.1542/peds.2020-0702 Epub 2020 Mar 16.

27. Yonker LM, Anne M, Neilan AM, Yannic Bartsch Y, et al. Pediatric Severe Acute Respiratory Syndrome Coronavirus 2 (SARS-CoV-2): Clinical Presentation, Infectivity, and Immune Responses. J Pediatr. 2020;227:45-52. e5. https://doi.org/10.1016/j.jpeds.2020.08.037.

28. Parri N, Magistà AM, Marchetti F, et al. CONFIDENCE and COVID-19 Italian pediatric study networks. Characteristic of COVID-19 infection in pediatric patients: early findings from two Italian pediatric research networks. Eur J Pediatr. 2020;179(8):1315-23.

29. Parri N, Lenge M, Cantoni B, et al. COVID-19 in 17 Italian pediatric emergency departments. Pediatrics. 2020;146(6):e20201235. https://doi.org/1 0.1542/peds.2020-1235.

\section{Publisher's Note}

Springer Nature remains neutral with regard to jurisdictional claims in published maps and institutional affiliations.

Ready to submit your research? Choose BMC and benefit from:

- fast, convenient online submission

- thorough peer review by experienced researchers in your field

- rapid publication on acceptance

- support for research data, including large and complex data types

- gold Open Access which fosters wider collaboration and increased citations

- maximum visibility for your research: over $100 \mathrm{M}$ website views per year

At $\mathrm{BMC}$, research is always in progress.

Learn more biomedcentral.com/submissions 